\title{
FUENTES POÉTICAS IMPRESAS: DE LA BIBLIOGRAFÍA MATERIAL A LA FILOLOGÍA*
}

\author{
Josep Lluís Martos \\ Universitat d'Alacant \\ jl.martos@ua.es
}

Si hablamos de cancioneros del siglo XV, pensamos en códices manuscritos y es que la crítica, cuando ha atendido a su materialidad y estructura, se ha centrado, sobre todo, en este modelo de transmisión de la poesía medieval. Se ha generado una importante tradición crítica que desgrana la génesis de las grandes colecciones poéticas a través de la comprensión de los códices, pero, frente a ello, los impresos poéticos han recibido poca atención como continentes de ese legado; $y$, cuando así ha sido, sobre todo se han atendido desde una perspectiva contextual, ni siquiera siempre de manera monográfica y/o profunda, a pesar de su importancia para la historia del libro y de los textos. Habría que plantearse por qué la filología se siente más cómoda ante la materialidad del códice que frente a la del impreso, al menos en general. Una serie de investigadoras e investigadores sí que se han acercado con convencimiento, pero, fundamentalmente, desde intereses de catalogación de los productos bibliográficos; sin embargo, es difícil de encontrar un análisis profundo de las fuentes, que tenga repercusiones filológicas y que, cuando así es, está lejos, en cualquier caso, de que esta sea una tendencia mayoritaria en los estudios de cancionero. Ese cierto divorcio entre la filología y la bibliografía material es algo menor, quizás, en el caso del romancero, especialmente por su difusión en pliegos sueltos y por el interés en este modelo editorial en sí. Todo ello está cambiando, especialmente desde estas primeras dos décadas del

${ }^{*}$ Este trabajo se enmarca dentro del proyecto Cancionero, romancero y fuentes impresas, del Ministerio de Economía, Industria y Competitividad (FFI2017-86313-P), financiado por la Agencia Estatal de Investigación (AEI) y el Fondo Europeo de Desarrollo Regional (FEDER/UE), del cual soy investigador principal. 
siglo XXI y en la última del milenio pasado, ante la eclosión de instrumentos bibliográficos, algunos de ellos de gran calado y solvencia. Este monográfico responde, así, a esta inercia: es fruto y espacio filológico para profundizar y avanzar en el estudio de esta línea de investigación que aúna bibliografía material y filología, que atiende a las fuentes poéticas impresas, como punto de partida para comprender y fijar críticamente los textos que contiene.

Un profundo conocimiento de los testimonios debe estar en la base de cualquier edición crítica de un texto medieval. Una primera fase ecdótica, la descriptio, que -como vengo reclamando desde hace años, ante la práctica de protocolos sin repercusión textual, como mero trámite desligado de la filología estricta- es necesaria para afrontar la fijación crítica de las obras literarias y, con más razón, la de los textos poéticos, por la singularidad de sus fuentes. Esa comunión entre materialidad y filología es lo que debemos entender como filología material; sin ella, los datos de la collatio externa y de la collatio codicum podrían llegar a ser insuficientes o, al menos, se verían mermados de cierto potencial crítico. Desde época muy temprana, ya en el siglo XVI, se desconfió de la genuinidad de los textos impresos y ese prejuicio ha llegado a menudo a su fijación crítica en la actualidad: en ocasiones, se ha primado el manuscrito ante el testimonio impreso por prevención, por antigüedad, por desconocimiento de los mecanismos de intervención en los textos al pasar a la imprenta o, lo que es peor, simplificando y limitando la labor filológica ante estas circunstancias y rechazando, así, testimonios que quizás esconden variantes y versiones de una cierta rentabilidad ecdótica. Pero, además, la imprenta antigua llega a generar, por su potencial de difusión, el canon de una obra poética, de un cancionero o del corpus de un autor.

Buena prueba de todo lo expuesto hasta aquí es que el cancionero de Juan del Encina, el cancionero incunable que más obras contiene y el único mayoritariamente profano, no cuenta aún con una edición crítica completa y solvente. Y ese es un gran olvido filológico, si no una autolimitación de la disciplina, que, en cualquier caso, afecta también al resto de cancioneros impresos. Hoy, en este monográfico, se da un paso decidido en este sentido, pues, entre otros trabajos, se reúnen en él artículos que estudian los tres grandes (y olvidados) cancioneros incunables castellanos: el Cancionero de Llavia (86*RL), el Cancionero de Zaragoza (92VC y 95VC) y el Cancionero de Juan del Encina (96JE). Comienzo por ellos, pero este número monográfico alcanza a otros testimonios poéticos incunables, muy desatendidos como fuentes y con distinta suerte en cuanto al estudio de los textos que transmiten: la Criança y virtuosa dotrina de Pedro de Gracia Dei (89*GD), La traslation del muy excellente doctor Chaton de Martín García Puyazuelo (90DC) y la 
Pasión trobada de Diego de San Pedro (95*PT). De esta última obra se establece su rica tradición textual a lo largo del siglo XvI y se estudian sus fuentes, unos límites cuatrocentistas que -con plena justificación, al tratarse de obras medievales o de tradición medieval- se transgreden en otros cuatro artículos: dos de ellos, con conclusiones que afectan a un número importante de pliegos post-incunables y otros dos centrados en impresos con romances de mediados del siglo XVI. Finalmente, cuatro artículos más dan el paso necesario al que supone el objetivo último de esta línea de investigación: la repercusión del conocimiento de las fuentes poéticas en la fijación crítica de los textos y en su estudio, desde perspectivas ecdóticas, lingüísticas y hermenéuticas.

Maria Mercè López Casas estudia la materialidad y la estructura interna de uno de los más tempranos cancioneros incunables: el Cancionero de Llavia $\left(86^{*} \mathrm{RL}\right)$, una antología de 24 poemas encabezada por Fernán Pérez de Guzmán, cuyo protagonismo en ella es, en cierta manera, una de sus razones de ser. Presenta un muy cuidado análisis material de la ideal copy de la edición, en todas sus facetas y con una atención especial al análisis del papel y las filigranas, para desembocar en rasgos que confirman su datación temprana en 1486, en el primer período de producción de Pablo Hurus. López Casas cataloga seis ejemplares conservados, frente al único que conocíamos por Brian Dutton, y los estudia, con especial atención al de la Real Biblioteca de El Escorial y a los dos de la Biblioteca Nacional de España. Nos ofrece la estructura interna de este cancionero incunable y la compara con la tabla inicial de obras, para justificar las aparentes disfunciones de contenidos, que no son tales, y proporcionarnos, finalmente, un apéndice en el que aporta todos los testimonios de cada poema, con datos de foliación y estructura métrica, que va mucho más allá de los meros contenidos de este cancionero y son el punto de partida para una collatio externa.

María Jesús Lacarra estudia el ciclo de sesenta xilografías del Cancionero de Zaragoza, a partir de la que debió de ser su primera edición con estampas (92VC), de cuyos ejemplares conservados puede obtener todas excepto una, que completa a partir de 95VC, una edición con solo tres cambios en los grabados respecto del programa de imágenes del impreso anterior. Este amplio corpus de imágenes es el primero de tales características en un impreso poético peninsular e, incluso, anterior a tres de los grandes productos ilustrados salidos de las prensas de los Hurus: la Cárcel de amor (1493), Las mujeres ilustres en romance (1494) y el Viaje de la Tierra Santa (1498). Establece la distribución de grabados por obras y, en ese recuento, sorprende que las Coplas de la Vita Christi de fray Íñigo solo contengan 7 frente a los $22 \mathrm{de}$ la Pasión trobada de Diego de San Pedro. Estudia la filiación de diferentes 
grupos de ilustraciones, a partir de modelos de origen germánico, como es el caso de los 12 grabados directamente copiados o inspirados a partir de otros del alemán Martin Schongauer, cuya influencia se había demostrado para impresos salidos del taller de los Hurus con posterioridad. Pero también, apunta hacia otros modelos germánicos, de Israhel van Meckenem, para dos tacos; hacia un ciclo de grabados neerlandeses, de claras diferencias estéticas, en otras seis estampas; o hacia grabados provenientes de la imprenta en Lyon, 6 de los cuales se incorporaron a unas Horae (sine notis) y otros 4 ilustraron una Legenda aurea latina impresa por Mathias Huss en 1486, que en este caso, quizás, incluso, se trató de los mismos tacos. No solo apunta Lacarra a los modelos y, con ello, a la filiación de las ilustraciones, sino también a sus usos en otras ediciones de los Hurus, previas o posteriores, y a su presencia en impresos burgaleses. Se interpreta la falta de un programa iconográfico uniforme y la reutilización de las estampas, para concluir que eran de propiedad de los Hurus y que «en torno a 1490, si no es antes, en el taller de los hermanos Hurus había artesanos capaces de producir copias de calidad».

El artículo de Ana M. ${ }^{a}$ Rodado presenta un estudio del Cancionero de Juan del Encina (96JE) que avanza notablemente en el conocimiento de esta importante colección poética incunable. Establece su historia bibliográfica y valora la atención prestada por los diferentes repertorios o catálogos, para desembocar en un estudio material del cancionero impreso que supera y concilia - o confirma- datos de aproximaciones anteriores. Es especialmente destacable la atención prestada al trabajo de composición e impaginación, muy cuidado y meditado en este incunable. Establece la estructura interna del extenso corpus de este cancionero impreso, en una tabla que recoge no solo rúbrica, íncipit, éxplicit y folios, sino también el número de identificación del catálogo de Brian Dutton y el esquema métrico de cada composición poética, unos materiales pensados para facilitar la investigación en cancionero. Justifica la ordenación de los materiales, que atiende a géneros, «de la prosa al verso, del verso lírico a las representaciones», sin duda bajo la supervisión del propio Encina. Y cataloga 6 ejemplares frente a los 2 a que hacía mención Dutton, quien no aportaba signatura del de la Real Biblioteca del Escorial e incorporaba un fantasma bibliográfico, al remitir como fondo a la Biblioteca Nacional de España en vez de a la Real Academia Española. Estos dos ejemplares, de El Escorial y de la RAE, son los que se estudian con mayor detenimiento, al haberse consultado directamente, mientras que se catalogan los datos indirectos de los otros cuatro.

La fuente poética 90DC es un pliego suelto, a cuyo estudio dedica su artículo Juan Francisco Mesa, quien se plantea, como punto de partida, las 
dificultades para abastar en su totalidad las diferentes familias ecdóticas del texto latino de los Disticha Catonis, pues la propia función de la obra llevó a la multiplicación de intervenciones textuales de tradición muy compleja y aún sin fijar completamente, para lo que reclama la necesidad de considerar también las traducciones al romance. Establece las cuatro traducciones castellanas, todas ellas llevadas a la imprenta, la segunda de las cuales es el texto recogido en el pliego poético 90DC: La traslation del muy excellente doctor Chaton, de Martín García Puyazuelo, quien data su composición en 1467. Desarrolla un estudio material del incunable y de sus tres ejemplares conservados, en el que se centra en un resolutivo análisis tipográfico, que enmarcaría el impreso en la imprenta zaragozana, quizás, incluso, en el taller de los Hurus, por unas características del diseño de los tipos de este impreso que solo encontramos en su producción. Del análisis del papel y sus filigranas, se deduce que es de fabricación hispánica, lo que contribuye a sustentar su hipótesis también desde esta perspectiva material. Un rasgo y otro, asimismo, lo llevan a concretar la impresión hacia finales de la década de los ochenta.

La Criança y virtuosa dotrina de Pedro de Gracia Dei se recoge en un impreso incunable, que conocemos por Brian Dutton como $89^{*} \mathrm{GD}$, al que Natalia A. Mangas Navarro dedica su artículo de manera monográfica. Estudia la materialidad del impreso y reconstruye la estructura colacional de la ideal copy, que, con 32 hojas, pasaría los límites de las 20 que, convencionalmente y como mucho, se consideran un pliego suelto, pues estas son, exclusivamente, las conservadas en el ejemplar único, mútilo del último cuaderno. A partir del estudio de las filigranas, la tipografía y las referencias internas de la obra, se adscribe este impreso al taller salmantino de Juan de Porras y Juan de Montejo, y se data hacia el año 1488, frente a la horquilla de 1486-1490 y ante una posible adscripción a la imprenta extremeña de Coria. Tales conclusiones son coherentes con los contextos salmantinos de la figura de Pedro de Gracia Dei y con su búsqueda de mecenazgo real, a través de esta obra y del Blasón, pues empieza a aparecer en documentación regia en 1490. El trabajo aporta también, a pesar de tratarse de un impreso con una sola obra, una muy detallada descripción interna de sus diferentes secciones y de las correspondientes rúbricas, así como un estudio de la materialidad del ejemplar $\mathrm{y}$, en estrecha relación con esta, la reconstrucción de su historia más reciente, desde su llegada al fondo en que se conserva actualmente.

M. ${ }^{a}$ Carmen Marín Pina estudia la difusión impresa de la Pasión trobada de Diego de San Pedro en los siglos XV y XvI, una tradición editorial que supone una versión muy diferente a la manuscrita, transmitida por HH1, el Cancionero de Oñate-Castañeda. Es probable que pudiese haber sido fruto 
de un proceso de abreviación y reescritura por parte de Diego de San Pedro, a la luz del grado de intervencionismo, que afecta, especialmente, al final de la obra, por lo que Marín Pina se alinea en la propuesta de Severin y Whinnom acerca de un posible pliego poético anterior a la tradición impresa conocida a día de hoy. La obra cuenta, durante este período, con tres ediciones del Cancionero de Zaragoza (91*VC, 92VC y 95VC) y con cinco pliegos sueltos, uno incunable, tres renacentistas y uno perdido de 1564: a) Salamanca, Leonardo Hutz y Lope Sanz, c. 1496; b) Burgos, c. 1530-1540; c) Lisboa o Coimbra, Germão Galharde, c. 1530; d) Sevilla, Juan Gómez, 1559; e) Burgos, 1564. La autora atiende a la transformación textual y material de la obra en sus testimonios impresos, pero, sobre todo, lo hace en cuanto a los paratextos iniciales relacionados con la dama o monja dedicataria y, especialmente, desarrolla un profundo estudio de la ilustración de los impresos, que, por su intensidad, los hace singularizarse frente al resto de pliegos poéticos de la época; e, incluso, como ha demostrado Lacarra en este mismo monográfico, la Pasión trobada destaca internamente en los cancioneros impresos $92 \mathrm{VC}$ y $95 \mathrm{VC}$, con 22 imágenes frente a las 7 de una obra mucho más extensa, como la que abre esta colección y, a menudo, le da nombre. Ante la recuperación de algunos testimonios recientemente, Marín Pina sospecha, con acierto, de la existencia de otros pliegos perdidos de la Pasión trobada, que pudieron salir de las prensas de los Cromberger o de Juan Varela de Salamanca y que habrían sido modelo de algunas de las ediciones conservadas.

El artículo de Marín Pina es, al atender a la tradición editorial de una obra concreta, un punto de encuentro de la tradición incunable con los impresos del siglo XVI. A la imprenta en el Quinientos, precisamente, dedican sus artículos Mario Garvin, Josep Lluís Martos, Laura Puerto Moro y Virginie Dumanoir desde una perspectiva que, como el bloque anterior, parte de la comunión entre bibliografía y filología.

Así, Mario Garvin presenta una propuesta teórica sobre los pliegos bifolios, que plantea la mismísima delimitación del término y que desemboca en una argumentación fundamentada en ejemplos ya documentados como tal por otras/os investigadoras/es y en otros aducidos por él, para demostrar los problemas de detección de unidades editoriales diferentes que provienen de un mismo acto de impresión, con lo que ello implica para un proceso de catalogación de las fuentes poéticas. Su punto de partida son las ediciones identificadas como RM476 y RM605, unos pliegos bifolios estudiados por Mercedes Fernández Valladares y Francisco Mendoza Díaz-Maroto, cuyos ejemplares conservados pertenecieron a la biblioteca de Hernando Colón. Y, a partir de ahí, desarrolla un detenido análisis de dos importantes corpus de 
pliegos poéticos quinientistas, para atender y delimitar los pliegos bifolios que contienen: el volumen Ant.Il.1402 de la Biblioteca Comunale Augusta de Perugia y la colección que perteneció a la Condesa de Campo de Alanje, conservada hoy en la Biblioteca Nacional de España. Alude, con ello, hasta once casos, lo que no solo supone un desarrollo argumental en sí para su tesis final, sino que tiene consecuencias en la propia identificación de esos productos editoriales independientes pero de impresión conjunta. No se queda en ellos, sino que aduce a otras ciertas anomalías, como Garvin mismo las define, que le hacen pensar en este modelo editorial y técnico, para reivindicar que la mera existencia de un impreso con dos hojas «no resulta criterio suficiente para determinar que se trataba de un bifolio [...], del mismo modo [que] tampoco cuatro hojas son signo inequívoco de que no estamos ante dos obras independientes».

El caso expuesto por Josep Lluís Martos es, precisamente, el contrario: el de dos impresos independientes, concebidos como unidad editorial, sin por ello perder la posibilidad de una venta individualizada de ambos, especialmente en el segundo de los casos, que está libre de referencias al primero. Se trata de una estrategia editorial y, así, comercial, que Martos documenta en dos ediciones incunables y en una del primer cuarto del siglo XVI, para centrarse en este trabajo en la edición conjunta de la Qüestión de amor y de la Cárcel de amor, formada por dos impresos (in)dependientes salidos del taller antuerpiense de Martín Nucio en 1546. Se analizan las referencias del primer producto impreso al segundo y, así, su dependencia; y se estudia la materialidad de ambos, que, en última instancia, caracteriza su independencia. En ese análisis, se revisan los diferentes rasgos que singularizan la edición de ambas obras en su tradición editorial y que las enmarcan en la producción de Nucio, para centrarse, sobre todo, en los usos tipográficos de elementos paratextuales y decorativos en su función en la organización de los impresos. Esto es especialmente importante para el segundo de ellos, el de la Cárcel de amor, que contiene tres secciones internas, correspondientes, respectivamente, a la obra de Diego de San Pedro, a la continuación de Nicolás Núñez y a unos poemas de remate, con tres romances y el cabo de un villancico. Más allá de la poesía incorporada a dos de las obras en prosa de esta edición, que singularizan el objeto de estudio frente al del resto de trabajos de este monográfico, el segundo de los impresos trae consigo un interés añadido como fuente poética: los poemas incorporados como remate provienen -pero no son una reproducción completa- de un pliego burgalés hoy perdido probablemente impreso por Juan de Junta y anterior a 1546, del que hay reedición de la segunda mitad del siglo XVI. 
Laura Puerto Moro revisa el proceso de popularización de la poesía de cancionero a través de pliegos sueltos y, con ello, estudia la eclosión de una vía de transmisión textual a la que no era ajena, en cualquier caso, la imprenta hispánica incunable. Este análisis, de amplio espectro, se centra en los pliegos poéticos de tema amoroso de las tres primeras décadas del siglo XVI, lo que conlleva, muy a menudo y sin embargo, el estudio de impresos posteriores relacionados con ellos. La autora parte de los nueve pliegos postincunables de tema amatorio, cuatro de los cuales recogen poesía de Garci Sánchez de Badajoz, tres de Juan del Encina, uno de Costana y otro de Quirós. Al contar con más de un impreso y tratarse de dos de los grandes poetas del cancionero cuatrocentista, Puerto Moro se centra en los dos primeros para establecer ciertos rasgos de su transmisión en pliegos sueltos, lo que acabará fijando, por un lado, su canon poético en este modelo de impresos y, por otro lado, la influencia de estos en productos posteriores. No se limita la autora a constatar la existencia de pliegos poéticos post-incunables deudores de los grandes cancioneros del siglo $\mathrm{xv}$, sino que su objetivo es «indagar en el cómo y de qué manera se produce el trasvase» desde esas grandes colecciones a este modelo de transmisión textual, en un proceso de «convergencia entre tradición "mayor" y "menor"». La poesía de los llamados «autores galantes intermedios», que siguen la tradición amatoria cancioneril, se acoge en pliegos de la tercera década del siglo XVI y posteriores, a excepción de la obra de Reinosa, con presencia ya en la imprenta post-incunable. La eclosión de estos autores en productos impresos de estas características es deudora, en última instancia, de la difusión editorial en pliegos de los grandes autores de cancionero, en los diferentes sentidos que desentraña Puerto Moro, hasta el punto de crear una tendencia -si no un canon- de modelo de contenidos y géneros, para lo que analiza los diez pliegos poéticos de Alonso de Salaya, que recogen, asimismo, otras tendencias poéticas generadas en el Quinientos.

Virginie Dumanoir se enfrenta a los paratextos de las ediciones quinientistas de los Quarenta cantos de Alonso de Fuentes, desde su princeps sevillana de 1550 hasta la de Alcalá de Henares de 1587. Aunque tenemos noticia de cinco ediciones, solo se conservan ejemplares de cuatro de ellas, que utiliza la autora para analizar y comparar sus portadas, dedicatorias y licencias, desde una perspectiva material e interna. Estos paratextos y peritextos, así como su propio formato en $4^{\circ}$ o en $8^{\circ}$, son inconstantes a lo largo de la tradición editorial de los Quarenta cantos y, a partir de esta investigación, conocemos con detalle su proceso de transformación que, en última instancia, es clara imagen del proceso de recepción que buscaban los diferentes impresores y que iba a ser cambiante durante la segunda mitad del siglo Xvi. Dumanoir 
sitúa los Quarenta cantos de Alonso de Fuentes, con todo ello, en el contexto editorial de libros de romances, que eclosiona con el Cancionero de romances en 1546 y que ya en 1550 ofrece esta colección de autor, que supone un precedente claro para la de Lorenzo de Sepúlveda.

El estudio de las fuentes poéticas impresas de los siglos XV y XVI desde una metodología que combina la bibliografía y la filología, los rasgos materiales con atención a los textos contenidos, es el punto de partida para la reflexión crítico-textual, como demuestran los trabajos de Casas Rigall y de Martín Pascual. Las decisiones ecdóticas deben fundamentarse en criterios externos e internos de las fuentes en combinación con los rasgos internos de los propios textos, desde su variación a su análisis literario y lingüístico. En este último sentido incide el artículo de Mahiques Climent, pues el editor de romances debe plantearse, desde el conocimiento y alcance del fenómeno, el mantenimiento o no de la -e paragógica. El trabajo de Martínez Pérez, finalmente, desarrolla el análisis literario de los textos de una colección impresa a partir de su estructura interna, como paso previo y no posterior a la fijación textual, pues, como ocurre con el resto de cancioneros incunables, aún no se cuenta con una edición crítica del Cancionero de Llavia. Este último grupo de trabajos incide, por tanto, en fases posteriores a la descriptio, para centrarse en la collatio codicum y en el análisis de los datos de variación desde los conocimientos lingüísticos y literarios, desde la filología en estado puro.

Juan Casas Rigall se enfrenta al papel de Hernán Núñez en las ediciones de 1499 y 1505 del Laberinto de Fortuna de Juan de Mena, para analizar su método de trabajo en la fijación, colación y glosas de esta obra, en un ejercicio de ecdótica antigua y humanística cuya idiosincrasia parte de una reunión y combinación de los postulados y técnicas aplicados a la filología clásica desde antiguo y en época humanística, con especial atención a Beroaldo y Poliziano. El autor describe los rasgos de la versión vulgata del Laberinto utilizada por Núñez como texto base, a partir de la edición sevillana de 1496, atribuida al taller de Ungut y Polono. Se sigue la tendencia de utilizar la edición anterior como original de imprenta, como en esta de 1496, en que se usó la zaragozana de 1489 y, en cuanto a esta última, así debió de ocurrir también con la princeps salmantina de $c$. 1486, a partir de la cual, por tanto, «el stemma de las ediciones humanísticas traza una única rama vertical, en donde cada nueva estampa basa su texto en la precedente». Casas Rigall estudia la manera de actuar de Núñez desde diferentes perspectivas, comparando los métodos aplicados en las ediciones de 1499 y 1505: sus notas críticas, más cerca de Beroaldo y de Servio que de Poliziano, en la línea de apuntes exegéticos; las enmiendas sugeridas en estas anotaciones, confinadas 
en ellas, según el modelo clásico, sin efecto en el propio texto, mientras que evoluciona y fluctúa el método, desde la advertencia a un posible error sin aportar la solución, hasta la incorporación al poema; los usos de la emendatio ope ingenii y de la emendatio ope codicum, sin anotación correspondiente; o el recurso a los hipotextos que suponen las fuentes, a los auctores, como vía para la justificación ecdótica. «En el tránsito de la Glosa de 1499 a 1505 perduran constantes en el concepto de Núñez, pero también novedades que afectan sobre todo al elemento crítico-textual» y, en esa evolución, «la paradoja es notable, según esto, porque el elogio de Poliziano desaparece cuando Núñez comienza a entrever el alcance de su método».

Llúcia Martín Pascual ofrece un estudio ecdótico completo de los testimonios impresos del segundo poema más extenso de Ausiàs March, el canto moral «Cobrir no pusch la dolor qui $\cdot \mathrm{m}$ turmenta», que conocemos por la tradición crítica de Amadeu Pagès como poema 112. Para ello, revisa la tradición previa, mediante la recensio de los 14 cancioneros manuscritos y la collatio externa de aquellos que conservan el poema en cuestión, teniendo en cuenta su presencia en la estructura interna de estos e, incluso, en la material, puesto que, en el caso de $G^{3}$, estamos ante una unidad codicológica independiente, incorporada de manera directa, mientras que en $H$ apunta a un antígrafo de estas características. En su llegada a la imprenta en 1539, con un corpus poético muy limitado cuantitativamente aún, se reordena temáticamente y esta tipología se mantiene en los cuatro cancioneros impresos que le siguen en $1543,1545,1555$ y 1560, todos ellos casi con la obra completa conocida de Ausiàs March. Martín Pascual analiza la presencia de este poema en la estructura interna de cada cancionero impreso, así como su impaginación en estas ediciones y su collatio externa, con la correspondiente constatación de omisiones y de reordenación de estrofas. Finalmente, completa su estudio ecdótico de los testimonios impresos con un análisis textual e interpretación de los datos más destacados que se derivan de la collatio codicum.

Joan Mahiques Climent se enfrenta al estudio de la -e paragógica en los romances carolingios impresos durante el período post-incunable, un rasgo lingüístico con consecuencias para la rima y la métrica, que se imposta en ocasiones de manera artificial, mientras que en otras es un arcaísmo lingüístico, que caracteriza la oralidad de los romances. Ese cariz arcaico del fenómeno influye en su caracterización estilística, hasta el punto de considerarlo Mahiques como «un precepto poético», un rasgo propio de los romances, que, en su paso a la escritura, consideran innecesario algunos impresores, como Jacobo Cromberger, frente a los pliegos burgaleses, en que alternan ambas soluciones, lo que, en última instancia, justificaría su origen. De su análisis de 
los pliegos poéticos carolingios, en los que solo cinco romances recurren de manera predominante a la rima grave paragógica, establece el autor de este trabajo tres tipos de palabras rima: «-áe e no paragógica (por ejemplo, emperante), -á e paragógica (por ejemplo, Beltrane), -á (por ejemplo, Beltrán)». A partir del estudio de porcentajes por romances, impresos y talleres, Mahiques determina el carácter original del fenómeno en fuentes sin duda orales y su tendencia a la eliminación en su paso a la imprenta, muy sistemática en los impresos de Cromberger, con alternancia en los pliegos burgaleses según el romance y sus antígrafos, cuando ya hay precedentes impresos, de lo que concluye que «Menéndez Pidal y otros estudiosos están en lo cierto cuando consideran que la -e paragógica no es un invento de los editores del siglo XVI, sino un fenómeno propio de los romances en los que se documenta».

Antonia Martínez Pérez analiza el género del decir en el Cancionero de Llavia, partiendo de la delimitación del propio corpus de estudio, que supone alrededor de una cuarta parte de las composiciones incorporadas al cancionero y que estaría formado de los siguientes poemas: las famosas Coplas a la muerte de su padre de Jorge Manrique (ID 0277), La coronación de Fernán Ruiz de Sevilla (ID 0116), dos decires de Gonzalo Martínez de Medina -«Dime quien eres tu grande Anibal» (ID 0511) y «Por desconoscentia se perdio la luz» (ID 6005) y otro de Fernán Sánchez de Talavera - «Señora muy linda sabed que vos amo» (ID 1664). Martínez Pérez analiza los rasgos individuales de cada uno de estos poemas, para establecer su relación y diálogo interno en cuanto a ciertos tópicos y concluir, con ello, la «continuidad temática y formal que contribuye a la gran coherencia doctrinal» del Cancionero de Llavia.

Esta colección de catorce artículos comparten, en definitiva, un objeto de estudio poco transitado en la investigación sobre poesía medieval: su atención a las fuentes poéticas impresas, desde la materialidad y estructuración del producto editorial, hasta sus repercusiones en la filología, todo ello sin compartimentos estancos que dificulten el avance científico. Estas aportaciones, sin lugar a dudas, contribuyen a ello y suponen un impulso decidido en esta línea de estudio, al que ha contribuido la Revista de Poética Medieval con este monográfico, en lo que esperamos que sea una inercia in crescendo en este campo de estudio. 